\title{
Hyperelastic Bone Involving the Washer Method
}

Kristin Jones

University of South Florida

\author{
Advisors: \\ Arcadii Grinshpan, Mathematics and Statistics \\ Olukemi Akintewe, Medical Engineering \\ Problem Suggested By: Olukemi Akintewe
}

Field of Study for Problem Suggester: Medical Engineering

Follow this and additional works at: https://digitalcommons.usf.edu/ujmm

Part of the Mathematics Commons

UJMM is an open access journal, free to authors and readers, and relies on your support: Donate Now

\section{Recommended Citation}

Jones, Kristin (2020) "Hyperelastic Bone Involving the Washer Method," Undergraduate Journal of Mathematical Modeling: One + Two: Vol. 11: Iss. 1, Article 3.

DOI: https://doi.org/10.5038/2326-3652.11.1.4922

Available at: https://digitalcommons.usf.edu/ujmm/vol11/iss1/3 


\title{
Hyperelastic Bone Involving the Washer Method
}

\begin{abstract}
The research conducted focuses on 3D printing and its application in medical equipment. A recent breakthrough in modern material science was made with the creation of hyperelastic bone. This exploration looks at how hyperelastic bone is created, the cost comparison to older tools, and the possible design for hyperelastic bone. Detailed calculations and descriptions are also included to explain the reasoning behind the work conducted.
\end{abstract}

\section{Keywords}

medical equipment, bionics, 3D printing, hyperelastic bone, volume, washer method

Creative Commons License

(c) (1)(9)

This work is licensed under a Creative Commons Attribution-Noncommercial-Share Alike 4.0 License. 


\section{PROBLEM STATEMENT}

To find a new innovative way to use $3 \mathrm{D}$ printing in bionics with a basic knowledge of integration.

\section{Motivation}

In this day and age, 3D printing has become more and more popular. From simple zipper taps to bionic eyes, 3D printed objects bring a new world of diversity and creativity to engineering. Calculus is used in engineering to find speeds and directions of motion, shapes and their volumes, and the rate of change of different funcitons. This research is focused on the application of 3D printing in medical devices using the general knowledge of calculus. Hyperelastic bones have become a more popular approach with a wide range of application. Unlike other biomaterials used in reconstruction, hyperelastic bone is extremely flexible and customized at little cost. For example, a titanium shoulder replacement would cost anywhere between $\$ 6,000$ and $\$ 22,000^{[9]}$. Another factor to consider with this former style is that a shoulder replacement may not fit quite right once the surgeon is in the operation. Finally, the shoulder replacement could limit the range of motion for the patient, even with proper physical therapy post-operation.

With the hyperelastic bone, the chemical makeup and product is so simple that it has the potential to cut down the prices tremendously. Surgeons can create and completely customize this product for each patient. If this product is not exactly the right shape when the patient is in the surgery, the material is easy to cut and fold ${ }^{[7]}$. The best feature of this product is that it is regenerative. With the implantation of hyperelastic bone, surrounding tissue will grow and include the material throughout the healing process. 
The goal of this research is to link the calculus to 3D printed bionic materials and products, specifically, hyperelastic bone.

\section{MATHEMATICAL DESCRIPTION AND SOLUTION APPROACH}

When 3D printing any material, there are many different mathematical aspects to consider (see Figure 1). The material will affect the rate of print and the temperature when the filament is printed. Hyperelastic bones are created with a common chemical found in bones, hydroxyapatite $\left(\mathrm{Ca}_{10}\left(\mathrm{PO}_{4}\right)_{6}(\mathrm{OH})_{2}\right)$. This material makes up about $90 \%$ of the $3 \mathrm{D}$ printed filament. The other $10 \%$ is polycaprolactone ${ }^{[1]}$. This material is biodegradable, allowing this overall $3 \mathrm{D}$ printed product to be safely placed and slowly integrated into the human body's system. The porous interior and open sides allow for tissue to flow in and build naturally. The beauty of this product is that it can be printed and cooled at room temperature. This decreases cost and time spent to create any sort of implants.

Hyperelastic bone proves to be a very versatile source, where it is more flexible and features a porous structure. The flexible material differs from other implants by its strength and longevity being increased. Other bone implants are solid and can be more brittle, becoming susceptible to breaking or causing pain in the patient. This pain can hold especially true in younger patients, who would have to undergo multiple surgeries as they outgrow the solid material, such as replacing a metal rod to brace the spine with a longer one. However, since hyperelastic bone is flexible, it can be designed to fit any space, while the porous structure promotes tissue and bone growth. The porous structure allows for the implant to be naturally integrated into the boy's structure while still providing support. As time passes, blood vessels, tissue, and even new bone 
will grow in these small crevices. By designing the structure to tiny holes throughout, it also saves time and money when producing.

Cost Comparison:

To help put into perspective the difference of costs and the benefits of hyperelastic bone over time, a small mathematical analysis of cost of production, surgery, and post-care is compiled.

Cranioplasty is a procedure where part of the skull was removed in a prior surgery and is now going to be replaced. Using older materials such as titanium can lead to infections and major complications post-operation ${ }^{[10]}$.

- Cost of cranioplasty using former technology:

- Cost of titanium: 15-22 USD/lb.

○ Cost of surgery ${ }^{[11]}$ : approximately 11,000 USD

○ Cost of stay in hospital ${ }^{[11]}$ : approximately 5,000 USD

- Total Cost: see Graph 1, (1)

- Cost of cranioplasty using hyperelastic bone ${ }^{[2]}$ : approximately $83 \mathrm{USD} / \mathrm{mL}$

○ Cost of surgery ${ }^{[11]}$ : approximately 11,000 USD

- Cost of stay in hospital ${ }^{[11]}$ : approximately 5,000 USD

- Total Cost of Cranioplasty: see Graph 2, (2)

Rate of print:

The rate of print is $275 \mathrm{~cm}^{3} /$ hour. To put this in perspective, let us say a patient has just had surgery where part of his/her skull is removed. Say that piece of the skull is the temporal: 
$3.02 \pm 0.785 \mathrm{~mm}$ thick ${ }^{[8]}$ and about a radius of $2 \mathrm{~cm}$. The time it would take to print a hyperelastic bone replacement would be 0.828 minutes. For more details on how it is found, see the APPENDIX, (3)-(7).

Personal Design, see the APPENDIX, (8)-(26):

The best part about 3D printing is that the user can easily design all sorts of odd shapes. With hyperelastic bones, they can be designed as more flat shapes for skull reconstruction or as open cylinder shapes for bone shaft fixation or ligament sleeves ${ }^{[2]}$. One thing that will be investigated more is a hyperelastic bone that will help with bone shaft fractures. The 3D shape can be graphed and rotated around the $y$-axis. To make the cylinder shape hollow, the washer method ${ }^{[12]}$ (see Figure 2) is used (8). The equation is the initial equation used for the graph that is rotated about the $y$-axis on the specified interval (see Figure 3). The maximum of this interval could be extended to $\frac{8 \pi}{5}$ if the desired product needs more curve on the base. The interval allows the user to use the washer method to find the volume and shape of this irregular cylinder. The purpose of the hyperelastic bone cylinder I designed is to be used as a ligament sleeve or fracture. The design would also incorporate a small vertical cut. The sleeve would then be able to open and gently snap over the desired area. After investigating the shape that would be formed, I realized that the shape would taper to a fine point, which could have the possibility of breaking off and not benefitting in the designed purpose. This prompted the change in the equations (9). The use of two complex tangent functions allows for a smooth curve both on the interior and exterior sides. The $y$ interval cuts off the two functions before reaching sharp points. The vertical cut would still be in place. However, there is an issue that appears when creating the new functions. By removing the interval, the specified lines of the tangent functions could lead to multiple possibilities. For this desired shape, we will be using the lines between $x=3$ and $x=6$ (rough 
estimate of placement). The area that would be rotated would fall between $y_{2}$ and $y_{1}$ (see Figure 4). However, the integral becomes extremely complex with the use of the two tangent functions (15). To make the calculations more user friendly, the equations are changed to a quadratic function (see Figure 5, (16)). The integral of the new functions is much easier to complete and the volume found is approximately 47.083 cubic meters (26). This final integration still uses the washer method. The upper bound of the interval can be extended to fit the desired length.

\section{DISCUSSION}

Hyperelastic bone is the future in orthopedic surgery. Its unique properties will allow for a treatment that can be tailored to each individual person and aid in recovery time. In the cost analysis it is important to note a few things. Although it may appear that hyperelastic bone is more costly, it is important to understand why. With a titanium implant, more complications can occur after the surgery, which most likely means a second operation. Hyperelastic bone is more expensive because it is a new technology, however it holds great properties such as promotion of regenerative growth of bone and tissue and can be fitted exactly to each individual patient. As more and more major hospitals start incorporating technology labs, 3D printers will begin to become a common piece of equipment in healthcare facilities thus lowering the costs. The personal design is something that has not yet been investigated or tested, but more of an original design. The cylinder made of hyperelastic bone would be used for long bone fractures. The design would be a cylinder that would pop into place. The curved design would help with fracture that may be located closer to the head (top of bone) or condyle (bottom of bone). This sort of design would most effectively be used in clean breaks rather than a shattered bone. The design would be a cylinder that would pop into place. By using hyperelastic bone, this will help promote bone and tissue reconstruction at the site of the fracture. 
I hope that once campus labs reopen to conduct more experiment with the exact shape and possibly using scanners to recreate the perfect shape for a specific bone structure. Some research has already been conducted on adding antibiotics to the mixture of hyperelastic bone. It would also be beneficial to investigate how that might affect the printing process and even storage. Could this be used in place of vaccination? With this new development, it will be interesting to see how the future unfolds for hyperelastic bone 3D printing.

\section{CONCLUSION AND RECOMMENDATIONS}

To conclude, 3D printing will lead the world to advancing modern science and medicine. With the use of calculus, engineers will be able to better understand the fundamental ideas surrounding 3D printing. Through this research, the analysis covers how 3D printing and calculus will further the technology behind hyperelastic bone material, a recent medical breakthrough. Current hyperelastic bone designs are most common in skull reconstruction. Its regenerative properties will help promote growth of new bone and tissue around the site of the implant. However, due to hyperelastic bone being a new technology, it can be more costly. Still, the benefits outweigh the costs, where some outdated implants may lead to infection and cannot be designed to fit exactly to each patient.

When creating the personal design, it would have been helpful to have to some real-life application when finding the best shape. Using a CAD program like solid works would better help engineers understand the structure in a better visualization. It would also be curious to see how the personal design would be 3D printed using a cheaper material, such as PLA filament. The shape of the personal design would have a more desirable outcome if the tangent equations for Figure 4 were used. However, calculating the integral of those equations proves to be more 
complex and involving approximation if they are continued. I want the personal design volume to be a shape that any person with a basic understanding of calculus could be able to follow the calculations and complete themselves.

\section{NOMENCLATURE}

\begin{tabular}{|c|c|c|}
\hline Symbol & Meaning & Units \\
\hline$V$ & Volume & $(\mathrm{cm})^{3}$ \\
\hline$r$ & radius & $\mathrm{cm}$ \\
\hline$h$ & height & $\mathrm{mm}, \mathrm{cm}$ \\
\hline$t$ & time & mour, \\
\hline$C$ & cost & $\mathrm{USD}$ \\
\hline Ti & Titanium & $\mathrm{na}$ \\
\hline HB & weight of & $\mathrm{mL}$ \\
\hline$x$ & Titanium & $\mathrm{kg}$ \\
\hline & Hyperelastic & \\
\hline & bount of $\mathrm{HB}$ & $\mathrm{ma}$ \\
\hline
\end{tabular}




\section{REFERENCES}

1. Adam E. Jakus, Alexandra L. Rutz, Sumanas W. Jordan, et al. 'Hyperelastic 'Bone': A Highly Versatile, Growth Factor-Free, Osteoregenerative, Scalable, and Surgically Friendly Biomaterial," Science Translational Medicine (2016, September 28): Vol. 8 Issue 358, 1-15; https://stm.sciencemag.org/content/8/358/358ra127/tab-pdf .

2. Acellular regenerative biomaterials; https://www.dimensioninx.com/biomaterials/products https://www.dimensioninx.com/hyperelastic-bone

3. Ling Wang, Jianfeng KangLing, Changning Sun, et al. "Mapping porous microstructures to yield desired mechanical properties for application in 3D printed bone scaffolds and orthopaedic implants," Materials and Design: (2017), Vol. 133 (5), 62-68; https://www.sciencedirect.com/science/article/abs/pii/S0264127517306822.

4. Yu-Hui Huang, Adam E. Jakus, Sumanas W. Jordan et al. “Three-Dimensionally Printed Hyperelastic Bone Scaffolds Accelerate Bone Regeneration in Critical-Size Calvarial Bone Defects," Plastic and Reconstructive Surgery, Journal of the American Society of Plastic Surgeons: (2019), Vol.: Vol. 143 (5), 1397-1407; DOI:

10.1097/PRS.0000000000005530

https://cdn.journals.lww.com/plasreconsurg/Abstract/2019/05000/Three_Dimensionally_Pr inted_Hyperelastic_Bone.24.aspx.

5. Ram Alluri, Adam Jakus, Sofia Bougioukli, et al. “3D printed hyperelastic ‘bone’ scaffolds and regional gene therapy: A novel approach to bone healing," Journal of Biomedical Materials Research Part A: (2018), Vol. 106 (4), 1104-1110. 
6. Riley Temple. "Hyperelastic Bone," Biomedical Engineering, University of Rhode Island (2018, August 15). The original paper, published in the Journal of Biomedical Materials Research is "3D printed hyperelastic "bone" scaffolds and regional gene therapy: A novel approach to bone healing" (DOI: 10.1002/jbm.a.36310; 21 December, 2017 ); BME 281 First Presentation, November 7, 2016.

7. Fay Oney. "Video: 3-D Printed 'Hyperelastic Bone' Regenerates Bone Tissue. https://ceramics.org/ceramic-tech-today/biomaterials/video-3-d-printed-hyperelasticbone-regenerates-bone-tissue," American Ceramic Society (2018, August 15).

8. Elizabeth M Lillie, Jillian E Urban, Ashley A Weaver, Alexander K Powers, and Joel D Stitzel1. "Estimation of skull table thickness with clinical CT and validation with microCT," Journal of Anatomy: (2015), 226(1), 73-80; Published online 2014, Dec 1. doi: 10.1111/joa.12259;

https://www.ncbi.nlm.nih.gov/pmc/articles/PMC4313900/.

9. Kherkher Pulaski. "How Much Does It Cost to Have Shoulder replaced?" https://ifspb.com/much-cost-shoulder-replaced/.

10. Jonathan Forbes. “A Cost Effective Cranioplasty Using 3D Printed Custom Skull Implants," UC Health Media Room, Co-written by UC College of Engineering and Applied Science (2019, December 10); https://www.uchealth.com/articles/a-cost-effective-cranioplasty-using-3d-printedcustom-skull-implants/. 
Undergraduate Journal of M athematical M odeling: One + Two, Vol. 11, Iss. 1 [2020], Art. 3

11. Mohammad Amir Mrad, Khalid Murrad, Oleh Antonyshyn. "Analyzing the Cost of Autogenous Cranioplasty Versus Custom-Made Patient-Specific Alloplastic Cranioplasty," The Journal of Craniofacial Surgery: (2017), Vol 28 (5), 1260-1263;

https://journals.lww.com/jcraniofacialsurgery/Abstract/2017/07000/Analyzing the Cos t_of_Autogenous_Cranioplasty.29.aspx.

12. James Stewart. Calculus: Early Transcendentals. Cengage Learning, 2016. 


\section{APPENDIX}
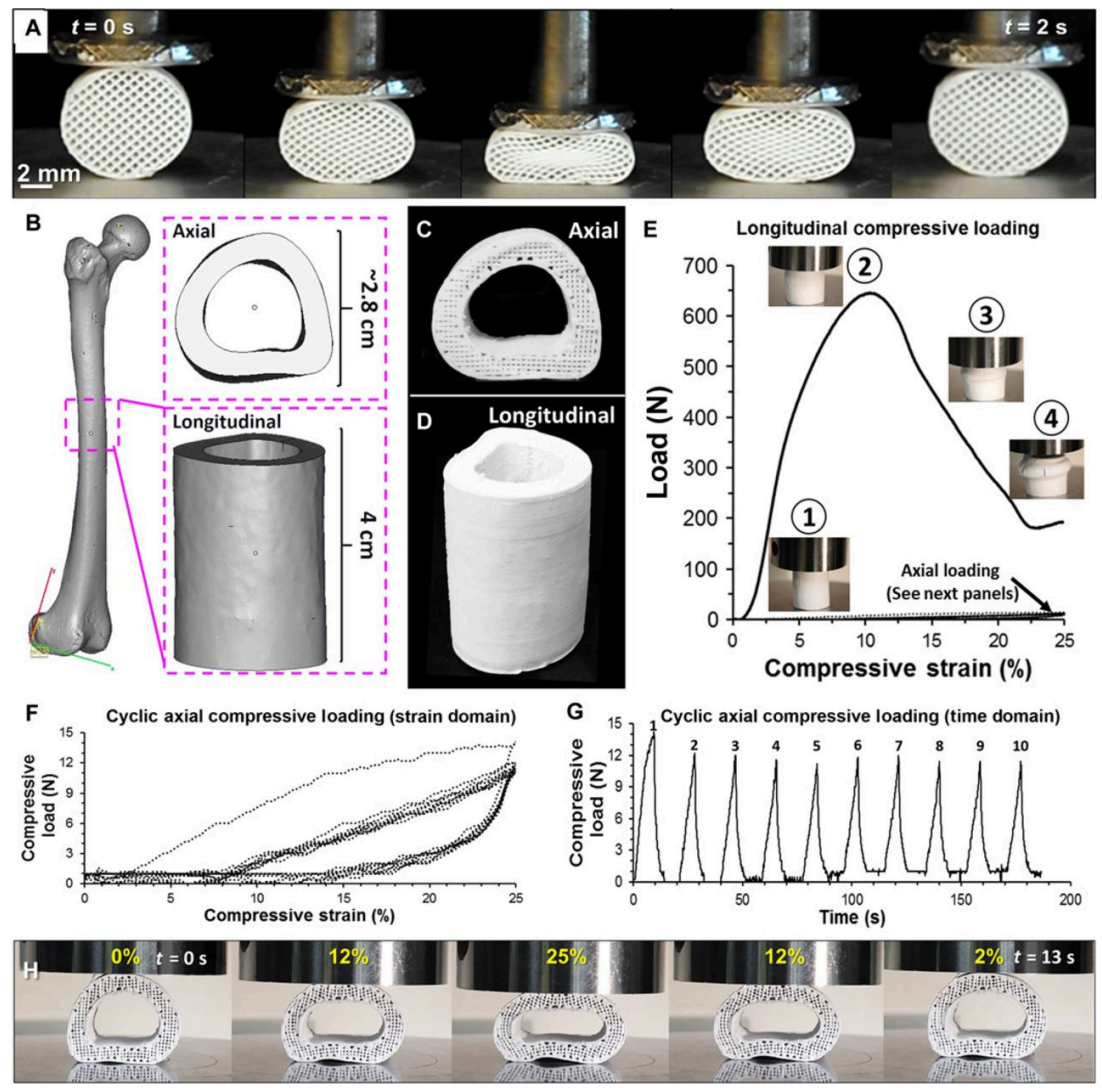

Figure 1: Additional General Information for $H B$

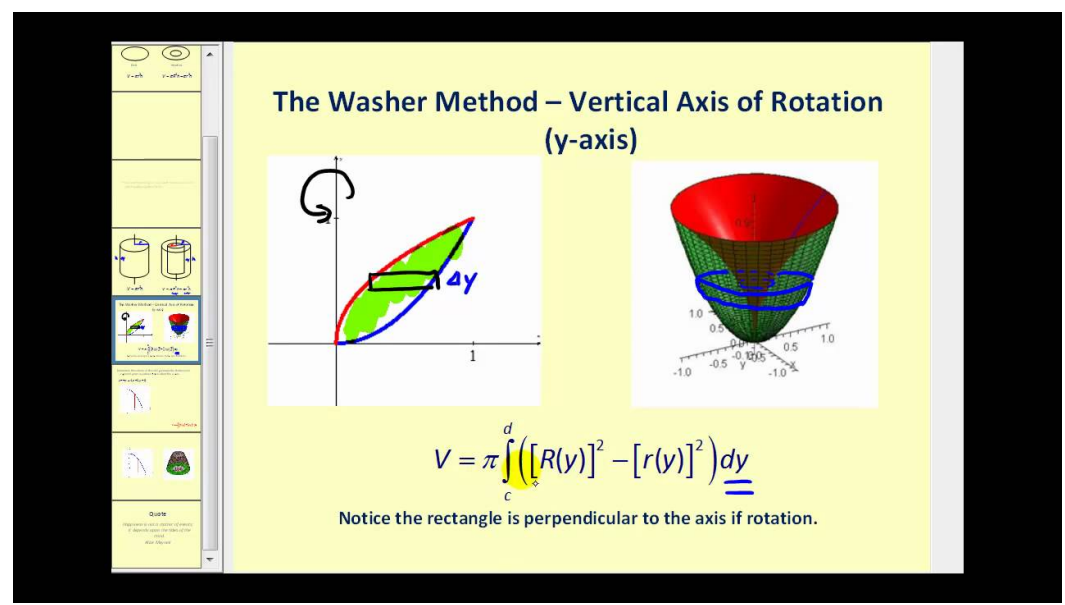

Figure 2: Example of Washer Method 


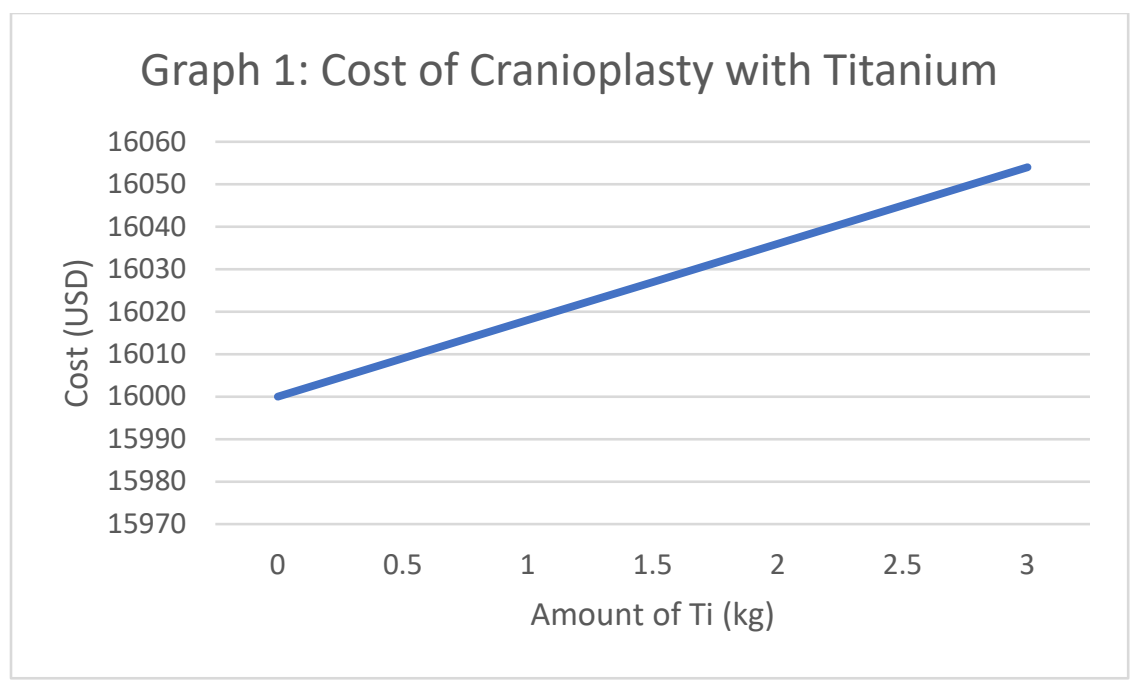

Equation of Graph 1: C=16000+18w (1)

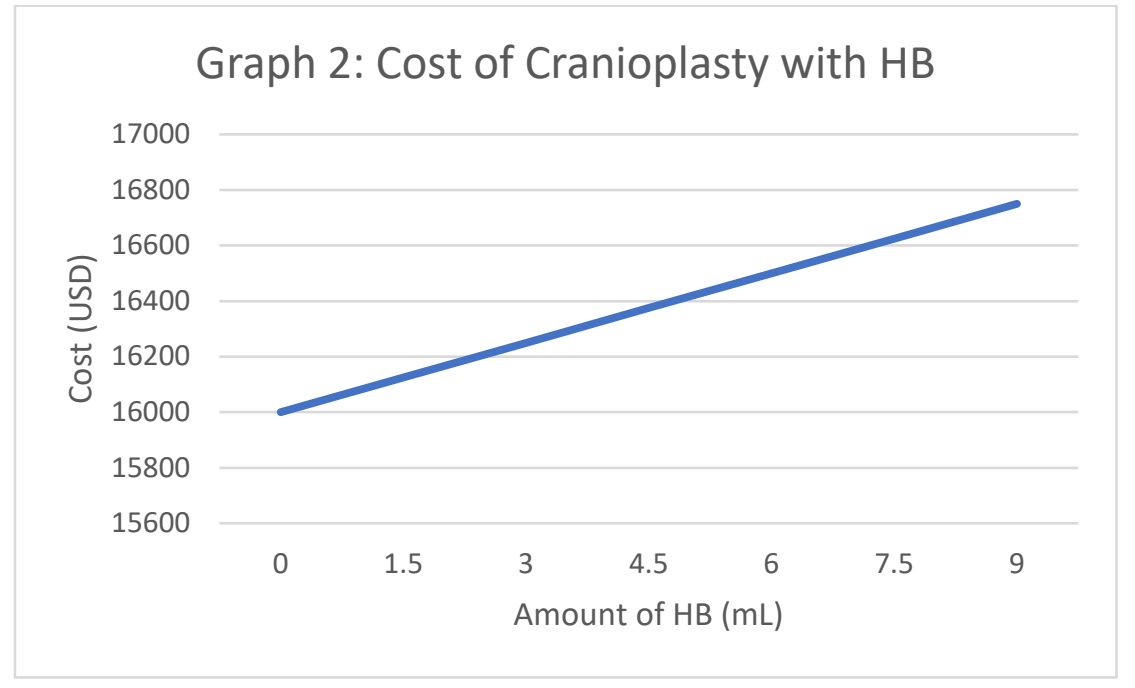

Equation of Graph 2: $\mathrm{C}=16000+83 x$ (2)

Temporal skull removal volume:

$V=\pi r^{2} h(3)$

$V=\pi(2 \mathrm{~cm})^{2}\left(3.02 \mathrm{~mm} \cdot \frac{1 \mathrm{~cm}}{10 \mathrm{~mm}}\right)$

$V \approx 3.79504(\mathrm{~cm})^{3}(\mathbf{5})$

Temporal removal time of printing: 
$t=\frac{3.79504 \mathrm{~cm}^{3}}{275 \frac{\mathrm{cm}^{3}}{\text { hour }}}(\mathbf{6})$

$t=0.0138$ hours $\approx 0.828 \min (7)$

Equations for Figure 3: $y=-4 \tan \left(x+\frac{\pi}{2}\right)=4 \cot (x), \frac{7 \pi}{6} \leq x \leq \frac{3 \pi}{2}$ about $x=0$ (8)

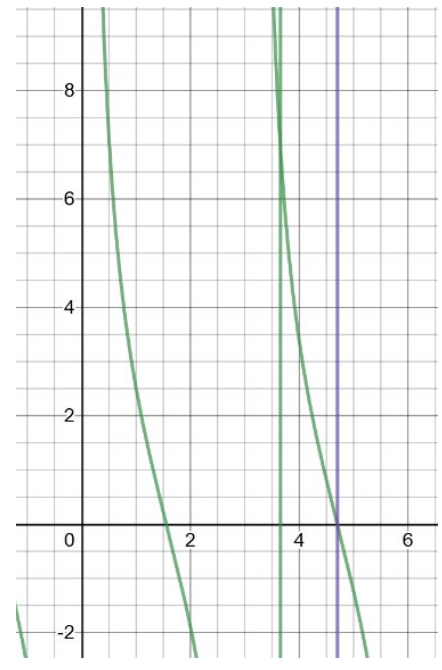

Figure 3: Initial Personal Design on 2D Graph

Equations for Figure 4: $y_{1}=-4 \tan \left(x+\frac{\pi}{2}\right)=4 \cot (x)$ or $x_{1}=\tan ^{-1}\left(-\frac{y}{4}\right)-\frac{\pi}{2}$ and $y_{2}=-3-4 \tan \left(x+\frac{\pi}{2}\right)=4 \cot (x)-3$ or $x_{2}=\tan ^{-1}\left(-\frac{y+3}{4}\right)-\frac{\pi}{2} ;$

$-6 \leq y \leq 5$ about $x=0(9)$

Note that: $x_{1}(y)=\tan ^{-1}\left(-\frac{y}{4}\right)-\frac{\pi}{2}>x_{2}(y)=\tan ^{-1}\left(-\frac{y+3}{4}\right)-\frac{\pi}{2}$,

however $x_{1}(y)^{2}<x_{2}(y)^{2}$ for $-6 \leq y \leq 5$. 


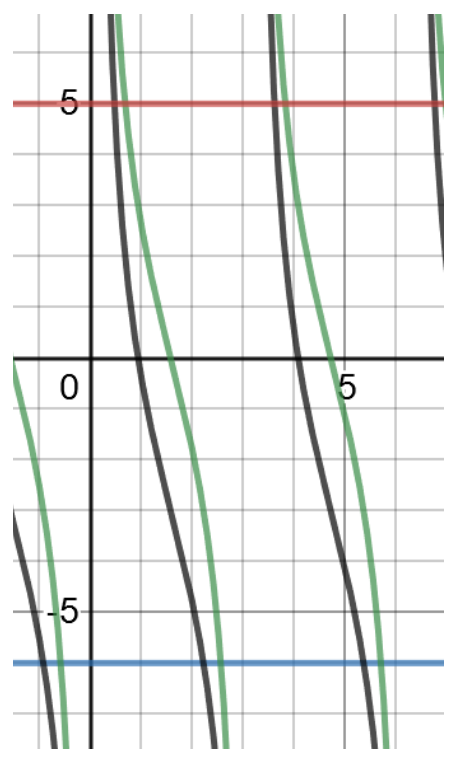

Figure 4: Second Personal Design 2D Graph

Personal Design Calculation Attempt 1, see (8), (9) and (10)-(15):

$V=\pi \int_{-6}^{5}\left[\left(\tan ^{-1}\left(-\frac{y+3}{4}\right)-\frac{\pi}{2}\right)^{2}-\left(\tan ^{-1}\left(-\frac{y}{4}\right)-\frac{\pi}{2}\right)^{2}\right] d y$

$$
\begin{aligned}
V= & \pi \int_{-6}^{5}\left(\left(\tan ^{-1}\left(-\frac{y+3}{4}\right)\right)^{2}-\pi \tan ^{-1}\left(-\frac{y+3}{4}\right)\right) d y \\
& -\pi \int_{-6}^{5}\left(\left(\tan ^{-1}\left(-\frac{y}{4}\right)\right)^{2}-\pi \tan ^{-1}\left(-\frac{y}{4}\right)\right) d y
\end{aligned}
$$

Side: $u=-\frac{y}{4}, v=-\frac{y+3}{4}$ (12)

Side: $d u=-\frac{1}{4} d y, d v=-\frac{1}{4} d y(\mathbf{1 3})$

Side: $u(-6)=\frac{3}{2}, u(5)=-\frac{5}{4}, v(-6)=\frac{3}{4}, v(5)=-2$ (14)

$V=4 \pi \int_{\frac{3}{2}}^{-\frac{5}{4}}\left(\left(\tan ^{-1}(u)\right)^{2}-\pi \tan ^{-1}(u)\right) d u-4 \pi \int_{\frac{3}{4}}^{-2}\left(\left(\tan ^{-1}(v)\right)^{2}-\pi \tan ^{-1}(v)\right) d v(\mathbf{1 5})$ 
Due to its complexity we use approximations in (15): $V \approx(-1.3153+$ $19.7017) \pi$. Hence $V \approx-4.1322+61.8948 \approx 57.763 m^{3}$.

Equations for Figure 5: $y_{1}=-7+5(x-4.25)^{2}$ or $x_{1}=\sqrt{\frac{y+7}{5}}+4.25$ and $y_{2}=-7+5(x-4)^{2}$ or $x_{2}=\sqrt{\frac{y+7}{5}}+4 ;-6 \leq y \leq 0$ about $x=0$ (16)

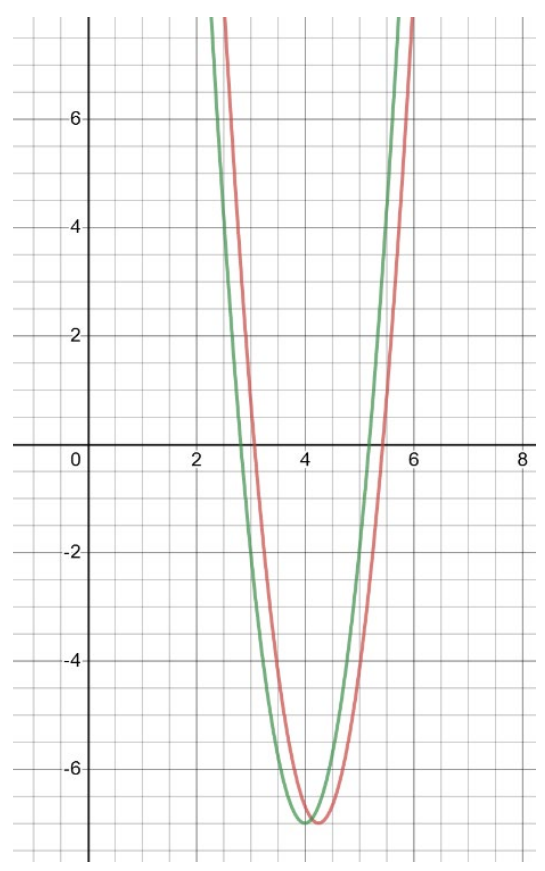

Figure 5: Final Personal Design 2D Graph

Final Personal Design Calculations, see (16) and (17)-(26):

$V=\pi \int_{-6}^{0}\left[\left(\sqrt{\frac{y+7}{5}}+4.25\right)^{2}-\left(\sqrt{\frac{y+7}{5}}+4\right)^{2}\right] d y(\mathbf{1 7})$

Side: $u=\frac{y+7}{5}(\mathbf{1 8})$

Side: $d u=\frac{1}{5} d y(\mathbf{1 9})$

Side: $\frac{1}{5} \leq u \leq \frac{7}{5}$ (20)

$V=5 \pi \int_{\frac{1}{5}}^{\frac{7}{5}}\left[\left(u^{\frac{1}{2}}+4.25\right)^{2}-\left(u^{\frac{1}{2}}+4\right)^{2}\right] d u(\mathbf{2 1})$ 


$$
\begin{aligned}
& V=5 \pi \int_{\frac{1}{5}}^{\frac{7}{5}}\left[\left(u+8.5 u^{\frac{1}{2}}+18.0625\right)-\left(u+8 u^{\frac{1}{2}}+16\right)\right] d u(\mathbf{2 2}) \\
& V=5 \pi \int_{\frac{1}{5}}^{\frac{7}{5}}\left[\left(0.5 u^{\frac{1}{2}}+2.0625\right)\right] d u(\mathbf{2 3 )} \\
& V=5 \pi\left[\frac{1}{3} u^{\frac{3}{2}}+2.0625 u\right] \text { from } \frac{1}{5} \leq u \leq \frac{7}{5} \mathbf{( 2 4 )} \\
& V=5 \pi[(0.5522+2.8875)-(0.0298+0.4125)] \mathbf{( 2 5 )} \\
& V=14.987 \pi \approx 47.083 \mathrm{~m}^{3} \mathbf{( 2 6 )}
\end{aligned}
$$

